\title{
OPTIMAL INEQUALITIES BETWEEN NEUMAN-SÁNDOR, CENTROIDAL AND HARMONIC MEANS
}

\section{WEIFENG XiA AND Yuming CHU}

Abstract. In this paper, we answer the question: what are the greatest values $\alpha_{1}, \alpha_{2}$ and the least values $\beta_{1}, \beta_{2}$, such that the inequalities

$$
\alpha_{1} T(a, b)+\left(1-\alpha_{1}\right) H(a, b)<R(a, b)<\beta_{1} T(a, b)+\left(1-\beta_{1}\right) H(a, b)
$$

and

$$
T^{\alpha_{2}}(a, b) H^{1-\alpha_{2}}(a, b)<R(a, b)<T^{\beta_{2}}(a, b) H^{1-\beta_{2}}(a, b)
$$

hold for all $a, b>0$ with $a \neq b$ ? Here, $R(a, b), T(a, b)$ and $H(a, b)$ denote the NeumanSándor, centroidal and harmonic means of two positive numbers $a$ and $b$, respectively.

Mathematics subject classification (2010): 26D15, 26E60.

Keywords and phrases: Neuman-Sándor mean, centroidal mean, harmonic mean, inequalities.

\section{REFERENCES}

[1] E. Neuman And J. SÁndor, On the Schwab-Borchardt mean, Math. Pannon., 14, 2 (2003), 253 266.

[2] E. Neuman And J. SÁndor, On the Schwab-Borchardt mean, II, Math. Pannon., 17, 1 (2006), 49-59.

[3] G. Pólya And G. Szegö, Isoperimetric Inequalities in Mathematical Physics, Princeton University Press, Princeton, 1951.

[4] H. Alzer AND S. L. QIU, Inequalities for means in two variables, Arch. Math. (Basel), 80, 2 (2003), 201-215.

[5] E. B. Leach And M. C. Sholander, Extended mean values II, J. Math. Anal. Appl., 92, 1 (1983), 207-223.

[6] T. P. LiN, The power mean and the logarithmic mean, Amer. Math. Monthly, 81 (1974), 879-883.

[7] H. J. SeIfFerT, Aufgabe $\beta$ 16, Die Wurzel, 29 (1995), 221-222.

[8] J. SÁNDOR, On refinements of certain inequalities for means, Arch. Math. (Brno), 31, 4 (1995), 279282.

[9] J. SÁndor, On certain inequalities for means II, J. Math. Anal. Appl., 199, 2 (1996), 629-635.

[10] J. SÁNDOR, On certain inequalities for means III, Arch. Math. (Basel), 76, 1 (2001), 34-40.

[11] E. Neuman And J. SÁndor, Generalized Heronian means, Math. Pannon., 19, 1 (2008), 57-70.

[12] E. NeumAn AND J. SÁNDOR, On certain means of two arguments and their extensions, Int. J. Math. Math. Sci., 16 (2003), 981-993.

[13] P. A. HÄSTÖ, Optimal inequalities between Seiffert's mean and power means, Math. Inequal. Appl., 7, 1 (2004), 47-53.

[14] E. Neuman, Inequalities for the Schwab-Borchardt mean and their applications, J. Math. Inequal., 5, 4 (2011), 601-609.

[15] Y. M. Chu, B. Y. Long, W. M. Gong AND Y. Q. Song, Sharp bounds for Seiffert and NeumanSándor means in terms of generalized logarithmic means, J. Inequal. Appl., 2013, (10) 2013, 13 pages.

[16] Y. M. LI, B. Y. Long AND Y. M. Chu, Sharp bounds for the Neuman-Sándor mean in terms of generalized logarithmic mean, J. Math. Inequal., 6, 4 (2012), 567-577.

[17] E. Neuman, A note on a certain bivariate mean, J. Math. Inequal., 6, 4 (2012), 637-643. 
[18] T. H. ZhaO, Y. M. ChU AND B. Y. LiU, Optimal bounds for Neuman-Sándor mean in terms of the convex combination of harmonic, geometric, quadratic, and contraharmonic means, Abstr. Appl. Anal., 2012, Article ID 302635, 9 pages.

[19] Y. M. ChU AND B. Y. Long, Bounds of the Neuman-Sándor mean using power and identric means, Abstr. Appl. Anal., 2013, Article ID 832591, 6 pages.

[20] W. F. XIA, W. JANOUS AND Y. M. CHU, The optimal convex combination bounds of arithmetic and harmonic means in terms of power mean, J. Math. Inequal., 6, 2 (2012), 241-248.

[21] Y. M. CHU, Y. F. QIU AND M. K. WANG, Hölder mean inequalities for the complete elliptic integrals, Integral Transforms Spec. Funct., 23, 7 (2012), 521-527.

[22] Y. M. ChU, M. K. WANG, Y. P. JiAng AND S. L. QIU, Concavity of the complete elliptic integrals of the second kind with respect to Hölder means, J. Math. Anal. Appl., 395, 2 (2012), 637-642.

[23] Y. M. CHU, M. K. WANG AND G. D. WANG, The optimal generalized logarithmic mean bounds for Seiffert's mean, Acta Math. Sci., 32B, 4 (2012), 1619-1626.

[24] Y. M. ChU AND M. K. WANG, Optimal Lehmer mean bounds for the Toader mean, Results Math., 61, 3-4 (2012), 223-229.

[25] Y. M. CHU, M. K. WANG AND S. L. QIU, Optimal combinations bounds of root-square and arithmetic means for Toader mean, Proc. Indian Acad. Sci. Math. Sci., 122, 1 (2012), 41-51.

[26] S. L. QIU, Y. F. QIU, M. K. WANG AND Y. M. CHU, Hölder mean inequalities for generalized Grötzsch ring and Hersch-Pfluger distortion functions, Math. Inequal. Appl., 15, 1 (2012), 237-245.

[27] M. K. WANG, Y. M. ChU, S. L. QIU AND Y. P. JiAnG, Convexity of the complete elliptic integrals of the first kind with respect to Hölder means, J. Math. Anal. Appl., 388, 2 (2012), 1141-1146.

[28] M. K. WANG, Z. K. WANG AND Y. M. CHU, An optimal double inequality between geometric and identric means, Appl. Math. Lett., 25, 3 (2012), 471-475.

[29] G. D. WANG, X. H. Zhang AND Y. M. ChU, A power mean inequality for the Grötzsch ring function, Math. Inequal. Appl., 14, 4 (2011), 833-837.

[30] M. K. WANG, Y. M. ChU, Y. F. QIU AND S. L. QIU, An optimal power mean inequality for the complete elliptic integrals, Appl. Math. Lett., 24, 6 (2011), 887-890.

[31] Y. M. CHU AND W. F. XIA, Two optimal double inequalities between power mean and logarithmic mean, Comput. Math. Appl., 60, 1 (2010), 83-89.

[32] W. F. XIA, Y. M. ChU AND G. D. WANG, The optimal upper and lower power mean bounds for a convex combination of the arithmetic and logarithmic means, Abstr. Appl. Anal., 2010, Article ID 604804, 9 pages. 